\title{
A indústria petrolífera na visão da Nova Economia Institucional: o caso da Petróleos de Venezuela (PDVSA)
}

\author{
Romina Batista de Lucena de Souza ${ }^{1}$ \\ Nali de Jesus de Souza ${ }^{2}$ \\ Stefano Florissi ${ }^{3}$
}

\begin{abstract}
Resumo: Este artigo analisa as estratégias de crescimento da empresa Petróleos de Venezuela (PDVSA) à luz da teoria da organização industrial. No segmento upstream, as associações da PDVSA são feitas na exploração e produção de petróleo na Venezuela, o que ampliou a posição competitiva da empresa através de economias de escala, acesso a novas tecnologias e equipamentos, compartilhamento de riscos, custos e lucros. No segmento downstream, a integração ocorre através de jointventures nas atividades de refino, estocagem, distribuição e comercialização de derivados. Essas estratégias consolidaram a indústria petrolífera venezuelana através de uma estrutura verticalmente integrada por associações, seguindo a lógica apontada pela nova economia institucional.
\end{abstract}

Palavras-chave: economia industrial; Nova Economia Institucional; Petróleos de Venezuela; integração vertical; custos de transação.

Abstract: This article analyzes the growth strategies of Petróleos de Venezuela (PDVSA) using an industrial organization theory. In the upstream segment PDVSA associations are done in the exploration and production of oil in Venezuela. This amplifies its competitive position through economies of scale, access to new technologies, equipment, risk, cost and profit sharing. The downstream segment integration happens through joint ventures in refining activities and stocking, distribution and commercialization of oil derivatives. These strategies have consolidated the Venezuelan Oil Industry through a vertically integrated structure of associations, following what would be expected in the logic of the new institutional economics.

Key words: industrial economics; New Institutional Economics; Petróleos de Venezuela; Vertical integration; transaction costs.

JEL: L14; L22

1 Professora do Departamento de Ciências Contábeis e Atuariais da UFRGS. Mestre em Economia e doutoranda em Desenvolvimento Econômico pela UFRGS. E-mail: rominabls@terra.com.br.

2 Professor do Programa de Pós-Graduação em Economia da PUCRS. Página WEB: nalijsouza.web.br.com. 3 Professor do Programa de Pós-Graduação em Economia da UFRGS. E-mail: florissi@portoweb.com.br. 


\section{Introdução}

O presente artigo visa resgatar, na literatura da organização industrial, as abordagens referentes à empresa enquanto instituição, tal como são apresentadas pela Nova Economia Institucional. Adotando-se os conceitos da mesma e de sua vertente, a teoria da economia dos custos de transação, apresenta-se o dinamismo da estratégia de integração vertical aplicado à indústria petrolífera venezuelana. O objetivo é analisar as estratégias de crescimento dessa indústria à luz da teoria da organização industrial, a fim de identificar as novas formas organizacionais estratégicas adotadas para obter competitividade no contexto da economia globalizada.

As novas formas organizacionais ocorrem através de associações entre empresas (jointventures), ou arrendamentos (leasing). Isso é feito tanto no segmento da integração vertical para trás (upstream) como no segmento da integração vertical para frente (downstream). No caso da PDVSA no segmento upstream, as associações são feitas na exploração e produção de petróleo na Venezuela. No segmento downstream, a integração é feita através de jointventures nas atividades de refino, estocagem, distribuição e comercialização de derivados (Rodrigues 1995:5). Exemplo pode ser dado pelos projetos de associações com a Petrobras para a implantação de um pólo petroquímico no Nordeste e um gasoduto para toda a América do Sul, visando abastecer especialmente o Brasil e a Argentina.

Vale lembrar que a abordagem da empresa pela Nova Economia Institucional tem como contribuição principal os estudos da teoria da firma desenvolvidos por Coase (1937). Esse autor busca uma definição de empresa "que corresponda ao que ela é no mundo real”. Essa nova visão de empresa deu início ao estudo das condições sob as quais os custos de transação deixam de ser desprezíveis e passam a ser importantes nas decisões dos agentes econômicos, contribuindo para determinar a forma pela qual são alocados os recursos na economia. Como a especificidade dos ativos eleva os custos de transação, é preciso incluir na discussão destes a análise sobre a verticalização das diferentes etapas do processo produtivo.

Para atingir os objetivos estabelecidos, o artigo divide-se em cinco seções, incluindo esta introdução. Na segunda seção, apresenta-se uma breve análise da evolução histórica da indústria de petróleo. Na terceira, são analisadas as estratégias disponíveis para as firmas nessa indústria, tanto do ponto de vista da abordagem neoclássica como sob a ótica da Nova Economia Institucional. A quarta parte apresenta a indústria petrolífera venezuelana, e estuda a PDVSA segundo a nova abordagem da Economia Institucional. Finalmente, na última seção, apresentam-se as considerações finais. 


\section{A organização da indústria mundial de petróleo}

Conforme Peterson (2004:32), o petróleo já era conhecido na Antiguidade. Os primeiros contatos do humano com esse produto e com o gás natural aconteceram na China em cerca de 1200 a.C. Os egípcios e os hebreus usavam o petróleo para embalsamar múmias e queimar animais nos sacrifícios religiosos. Porém, foi somente em 1859 que Edwin Drake usou o petróleo para fins comerciais. A partir de então, esse produto tem sido utilizado cada vez mais pela indústria e pelo transporte como fonte de energia, em substituição ao carvão; nenhum insumo tornou-se tão essencial para o homem e nenhum gerou uma diversidade tão ampla de produtos como o "ouro negro"; nenhuma indústria foi tão essencial à economia mundial e tão vinculada à política internacional quanto a indústria petrolífera (Marinho Júnior 1989:15).

Em 1870, a indústria de petróleo começou a se organizar como grande indústria, através da companhia Standart Oil, de John D. Rockfeller. Essa empresa introduziu uma grande mudança na forma de atuação da indústria, através da integração vertical. A indústria petroleira foi, portanto, uma das primeiras indústrias a atuar integrada na forma vertical. ${ }^{4}$ Nesse período, a Standart Oil controlava oleodutos e ferrovias, o que minimizava as flutuações de preços e mantinha altas margens de lucro. A estratégia de integração vertical da empresa, que ainda não atuava na exploração e produção de petróleo, foi fundamental para o sucesso dessa companhia na comercialização do produto. Com o controle comercial, a Standard Oil 5 tornouse a primeira grande empresa monopolista da época. Dessa forma, projetaram-se os alicerces da estrutura dentro de características econômicas básicas, que ainda hoje regem a indústria petrolífera: a integração vertical e o monopólio.

Mesmo com o desmembramento da Standard Oil, o desenvolvimento da indústria americana de petróleo ainda prosseguiu com a presença das grandes majors do petróleo (as Sete Irmãs): Exxon, Royal Dutch-Shell, British Petroleum, Gulf Oil, Chevron, Móbil Oil e Texaco. Elas eram empresas internacionalizadas e integradas verticalmente a companhias menores, especializadas em apenas um dos segmentos da cadeia petrolífera. Essa internacionalização da indústria de petróleo aumentou a relevância da competição estratégica no oligopólio internacional das majors sobre o controle do mercado mundial, coordenando as atividades e aumentando as barreiras à entrada. (Canelas 2004)

A partir da formação do cartel das Sete Irmãs, considerado um modelo de regulação privada, ocorreu uma expansão relativamente estável do setor, interrompida pelo primeiro choque do petróleo de 1973. Com esse choque, declinou o controle da indústria pelas Sete Irmãs, pois a partir desse momento a indústria de petróleo passou a apresentar uma crescente característica de desintegração, tanto horizontal quanto verticalmente.

4 Emprega-se a expressão integração vertical para indicar que uma empresa participa de todas as etapas do processo produtivo. A integração vertical pode ser enfocada por duas óticas: industrial (exploração e produção de óleo) e econômica (refino, transporte, petroquímica básica e distribuição de derivados). A integração permite diminuir os riscos da atividade empresarial (Petrobras apud Campos 2005:31). 5 Em 1911, a Suprema Corte dos Estados Unidos obrigou a Standart Oil a desmembrar-se em 33 empresas distintas. 
O enfraquecimento das majors, conseqüentemente, fortaleceu o poder da Organização dos Países Exportadores de Petróleo (OPEP), organização fundada em 14/9/1960 pelos maiores países produtores de petróleo. ${ }^{6}$ A OPEP constatou em seguida que, através de seu poder de mercado, poderia exercer grande controle sobre o setor petrolífero mundial. A estatização das empresas petrolíferas pelos países membros da OPEP e o primeiro choque do petróleo em 1973 representaram um ponto drástico de mudança de estrutura da indústria do petróleo. O controle da indústria pelas Sete Irmãs desarticulou-se gradativamente, tanto no nível nos segmentos para trás como para frente da cadeia produtiva, representando elevação dos custos de transação na avaliação de Canelas (2004:26).

O segundo choque do petróleo de 1979 decorreu de razões políticas, agravando substancialmente os déficits comerciais dos países importadores, dada a quadruplicação do preço do petróleo. Esses dois choques foram dramáticos para esses países, provocando profundas modificações estruturais na economia mundial. Foi somente na década de 1980, pelo excesso de oferta, que os preços do petróleo começaram a cair no mercado mundial, limitando o poder de mercado da OPEP. Contribuiu nesse sentido a exploração de petróleo em outros países e o surgimento de energias alternativas (como álcool, carvão, energia eólica, entre outras). Essa queda de preço freou o crescimento da atividade petrolífera e diminuiu a sua lucratividade.

As transformações da matriz energética mundial e as mudanças da indústria petrolífera levaram a um redirecionamento de suas estratégias organizacionais, especificamente aquelas relativas à integração vertical, que reduzem os custos de transação.

\section{Estratégias organizacionais na indústria petrolífera}

O estudo das estratégias organizacionais, pela abordagem da Nova Economia Institucional, parte especificamente da integração vertical e dos custos de transação. Porém, antes é necessário analisar a abordagem referente ao papel reservado às empresas na economia capitalista, sob a ótica tradicional da teoria neoclássica da firma, que forma a base de onde parte a crítica da Nova Economia Institucional.

\subsection{A teoria neoclássica da firma}

A teoria econômica neoclássica considera que a coordenação das ações dos agentes é dada pelo sistema de preços. Nessa abordagem, dividem-se os agentes de mercado como formadores de preços (price makers) e tomadores de preços (price takers). Essa teoria permite explicar a existência dos preços 
como uma função da preferência dos consumidores e da tecnologia disponível no processo de produção. O conceito de firma, de acordo com essa teoria, se limita ao de um agente econômico que se organiza, dada a tecnologia existente, para produzir e ofertar bens e serviços.

Assim, pela teoria neoclássica, a empresa é o local onde se combinam os fatores de produção de maneira a gerar os produtos, sendo essa produção sujeita às leis dos rendimentos decrescentes. Essa abordagem, no entanto, é incapaz de reconhecer a importância do "empreendedor", e do fato de que este é o agente que toma as decisões dominantes da vida econômica. Por essa abordagem, a firma é vista como um agente individual, um ator passivo sem autonomia, preocupado apenas com o sistema de preços (Tigre 2005).

Especificamente, na situação de concorrência perfeita, e na ausência de progresso técnico, a firma tem poucas escolhas e se detém a maximizar lucros buscando a melhor alocação de recursos entre usos alternativos. Outro aspecto importante da situação de concorrência perfeita é a de que as decisões ocorrem de forma isolada em relação ao restante do mercado; não há feedback entre as firmas, tanto entre concorrentes como ao longo da cadeia produtiva; portanto, o ajuste da produção ocorre exclusivamente através dos preços (Macadar 2005).

Na visão da Nova Economia Institucional, pelo contrário, o papel das firmas é mais significante e completo. A compreensão da atividade econômica e das empresas como agentes pode ser, nesta, aprofundada através de considerações acerca das instituições, como veremos a seguir.

\subsection{A Nova Economia Institucional}

Em seu artigo "Transaction cost economics”, Williamson (1989) faz uma abordagem interdisciplinar do custo de transação, a qual é conhecida como Nova Economia Institucional. Esta teve como principal contribuição os estudos da teoria da firma, desenvolvidos por Coase (1937).

A Nova Economia Institucional aborda a análise dos atributos formais (leis, política e justiça) e informais (termos contratuais), bem como as estruturas de governança (mercados, firmas e agências) envolvidas nas transações e nas garantias à sua performance. O grande avanço dessa abordagem está no tratamento dos diferentes arranjos verticais, contidos entre a integração vertical das atividades e a contratação, no qual a complexidade das relações contratuais e a racionalidade limitada dos agentes impedem a redação de contratos completos.

Williamson (1989) inicia o estudo da economia dos custos de transação colocando o problema da organização econômica como sendo um problema contratual. Nessa concepção, o autor baseia o estudo nas suposições de racionalidade limitada e de oportunismo dos contratos, como contrapontos às suposições tradicionais de racionalidade ilimitada e de honestidade. As 
suposições de racionalidade limitada e de oportunismo são tão importantes nesse contexto que formam a base para distinguir, por exemplo, entre os modelos de contratos factíveis e não-factíveis. ${ }^{7}$ A indústria do petróleo apresenta altos riscos, principalmente no segmento upstream, pela aleatoriedade da extração do produto, e necessita de grande volume de capitais, grande período de maturação dos investimentos, de sorte que há uma tendência a redistribuir os riscos entre todos os segmentos da cadeia, apresentando assim alta propensão ao oportunismo. Macher \& Richman (2006:16) argumentam que, em razão da grande incerteza dessa indústria acerca das condições geológicas e econômicas, elas estão sujeitas a risco moral.

Para ele, o custo de transação determina a utilização dos contratos e o grau de verticalização das firmas. Os contratos são essenciais e a partir deles as firmas determinam a forma da produção e sua organização. A firma, para esse autor, assim como para Coase, é uma estrutura de governança, ao invés de uma função de produção, como para os neoclássicos.

A suposição da racionalidade limitada elimina a possibilidade de que os contratos sejam feitos de forma completa ex ante; ou seja, de acordo com essa suposição, todos os contratos são incompletos; portanto, vale o comportamento ex post e os estudos das instituições e dos custos de transação, fatores completamente ignorados pela análise neoclássica tradicional e que ganham importância fundamental. A essência desses custos reside no estudo dos direitos de propriedade, que passam a balizar os contratos e as instituições. A proposta do autor é verificar como as instituições (englobando contratos, firmas e mercados) lidam com os problemas vinculados aos custos de transação, que envolvem, por exemplo, freqüência, incerteza e especificidade dos ativos.

Com relação à especificidade dos ativos, o autor explica que estes são ditos específicos quando não podem ser reempregados para outro uso, sem que isso implique perda de valor. Williamson identifica quatro tipos de ativos específicos: a) especificidade locacional, b) especificidade de ativo físico, c) especificidade de ativo humano e d) ativos dedicados. No caso da indústria petrolífera, os ativos se concentram nos locais de extração petrolífera, estando condicionados à localização das jazidas; já no segmento downstream, nas atividades de refino, a tendência é a localização mais próxima possível dos consumidores. Com isso, minimizam-se os custos de transação.

Uma outra importante contribuição de Williamson foi a reflexão sobre os determinantes das inovações organizacionais em direção à integração vertical, que surge para economizar os custos de transação. A especificidade do ativo constitui o principal fator para a decisão de integração vertical. Quando ela for pequena (ou fraca), as relações através do mercado são preferíveis; quando ela for grande (ou forte), a integração vertical torna-se a melhor alternativa. 
Williamson observou que a opção pela integração vertical reduz os custos de transação, ao permitir à firma ativar uma maior variedade de processos sensatos de incentivos e controles do que seria possível se lidasse com unidades autônomas ou semi-autônomas. Em segundo lugar, a integração vertical reduz os conflitos instrumentais, como aqueles derivados, por exemplo, do oportunismo. À medida que a firma incorpora etapas produtivas sob um mesmo comando, diminui, ou até elimina, a necessidade de arcar com os custos contratuais que visam lidar com os custos de transação gerados por terceiros. $\mathrm{Na}$ indústria petrolífera, que envolve pesados investimentos de alto risco e grandes transações ao longo da cadeia produtiva, implementadas através de contratos de longo prazo, a integração vertical constitui uma forma de organização que minimiza os custos de transação (Macher \& Richman 2006:17). Assim sendo, essa forma de integração aparece como uma das estratégias organizacionais da indústria petrolífera, em que os custos de transação da terceirização são particularmente intensos.

\subsubsection{A integração vertical na indústria petrolífera}

No caso das empresas de petróleo, a integração vertical é uma estratégia bastante comum. Ela evita as incertezas dos mercados intermediários, permitindo o gerenciamento do fluxo do petróleo e dos produtos refinados, desde a extração até o consumidor final. Esse problema ocorre porque, ao operacionalizar qualquer transação, os agentes têm a incerteza em relação aos seus resultados.

Essa integração, por sua vez, permite distribuir os riscos e os custos entre os vários segmentos da cadeia produtiva. Devido à incerteza, os níveis de riscos e os altos investimentos requeridos nessa atividade, a integração vertical permite saídas de mercado garantidas para o refinador e ofertas garantidas para o distribuidor. Essa é a razão pela qual a indústria de petróleo atua de forma oligopolizada e diversificada internacionalmente; isso permite às grandes empresas do setor o domínio do mercado mundial de petróleo, integrando verticalmente as suas atividades, desde a pesquisa, a exploração e a produção (segmento upstream) até o transporte, o refino e a distribuição de produtos (segmento downstream) (Campos 2005:31).

A indústria de petróleo, é preciso lembrar, possui particularidades que a caracteriza como oligopolista: produto inelástico em relação ao preço, grandes barreiras à entrada e alto volume de capital necessário, tanto para a atividade como para o acesso à matéria-prima básica. $\mathrm{O}$ acesso à matéria-prima é um dos fatores mais importantes na decisão da integração vertical. As empresas de petróleo, ao invés de buscarem maior margem de lucro para cada etapa da cadeia, passam a maximizar o retorno da cadeia de petróleo como um todo. Desse modo, as refinarias teriam menos incertezas em relação ao suprimento de matérias-primas se a produção fosse feita pela mesma empresa. Da mesma forma, haveria garantia de escoamento da produção, tanto em direção às refinarias como posteriormente em direção à comercialização, o que levaria 
a um melhor planejamento da produção. Logo, a questão da harmonia entre os segmentos upstream e downstream tem sido o grande foco das empresas petrolíferas.

Essa indústria destaca-se, portanto, pela importância da economia de integração: com alta especificidade de ativos, que implicam grandes custos transacionais entre os agentes. Estes são os chamados custos de transação, tema apresentado a seguir, tendo como principal referencial teórico o artigo de Ronald Coase, "The nature of the firm", que mudou a maneira de se ver a organização econômica (Coase 1937).

\subsubsection{Custos de transação}

Em seu artigo, Coase (1937) enfatizou a importância de se compreender corretamente o funcionamento do sistema econômico para poder definir corretamente a firma. Ele lembrou que o sistema econômico é coordenado pelo mecanismo de preço e que o traço distintivo da firma é a supressão desse mecanismo, uma vez que, "no interior da firma essas transações de mercado são eliminadas e a complexa estrutura de mercado, com suas transações de trocas, é substituída pelo empresário-coordenador, que dirige a produção" (Coase 1937:388). Para Coase, portanto, as firmas agem por um sistema de contratos e não meramente por um sistema de preços.

Seguindo essa percepção, as firmas estão se tornando cada vez maiores do ponto de vista do número de indivíduos e dos fatores de produção; por isso, as firmas realizam cada vez mais contratos de mercado em determinado sistema produtivo. O problema da firma emerge dos custos de se usar o mercado, de descobrir os preços relevantes, de negociar e concluir um contrato para cada transação, de maneira a garantir o seu cumprimento (Fiani 2002:269). Emerge, assim, a questão dos custos de transação, o principal fator desta análise.

Nessa abordagem, o custo de “organizar" a produção, através do mecanismo de preço, decorre da necessidade de descobrir os preços relevantes. Esses custos decorrem, principalmente, da existência de contratos incompletos, de longo prazo, pela incerteza e dificuldade de previsão. A incerteza aumenta os custos e, nessas condições, ela afeta o comportamento econômico.

Assim, Coase deu início ao estudo das condições sob as quais os custos de transação deixam de ser desprezíveis e passam a ser um elemento importante nas decisões dos agentes econômicos, contribuindo para determinar como são alocados os recursos na economia. Ele observou que os custos da organização interna estão ligados diretamente aos seguintes casos: (a) aumento da dispersão espacial das transações pelas firmas; (b) aumento da diversidade entre essas transações; (c) aumento da probabilidade de mudanças dos preços relevantes às atividades. 
Em síntese, dois pontos-chave apontados por Coase reformularam a visão da firma pelo entendimento de que: (a) uma de suas características básicas é adoção de contratos, e (b) o mercado também tem custos - denominados "custos de transação".

Uma grande diferença entre a análise dos custos de transação e a abordagem neoclássica é que, na primeira, os aspectos comportamentais são mais profundamente analisados. Seguindo a análise de Simon, citado por Williamson (1989:139), os agentes têm racionalidade limitada. Ao buscar seus próprios interesses, eles também podem ter comportamentos oportunistas, em decorrência da assimetria da informação. Um agente pode usar essa assimetria para obter vantagens em relação a um outro.

Neste trabalho, a análise da empresa Petróleos de Venezuela seguirá a nova abordagem da economia institucional, na qual se incluem a teoria da integração vertical e dos custos de transação. Inicialmente, será apresentada uma pequena evolução da indústria de petróleo na Venezuela; a seguir, será estudada a estrutura organizacional dessa empresa.

\section{O caso da empresa Petróleos de Venezuela S.A. (PDVSA)}

A América Latina e o Caribe concentram 10,6\% das reservas mundiais de petróleo, sendo a Venezuela o país com o maior potencial de extração de petróleo da região, com $70 \%$ das reservas regionais. Toda a região consome, no entanto, apenas 6,4 milhões de barris diários de petróleo, o equivalente a 8,4\% do consumo mundial (Caro 2003).

Dentro desse contexto, a Venezuela aparece como um dos maiores países da América do Sul, com quase 27 milhões de habitantes, distribuídos especialmente por grandes cidades, como Caracas, Maracaibo e Valencia. Em 2005, o PIB do país alcançou US\$ 131 bilhões (Aladi 2007); aproximadamente dois terços desse PIB vêm da exploração de petróleo, que gera cerca de dois terços da arrecadação fiscal do país. As reservas de petróleo e gás venezuelanas colocam o país em quinto lugar entre os grandes produtores mundiais. Esse recurso natural tem, portanto, grande peso na economia venezuelana, sendo responsável por cerca de $80 \%$ do total de suas exportações, o que vem explicando o dinamismo do crescimento econômico nacional nos últimos anos (Marcano \& Tyszka 2006).

\subsection{Constituição e modo de operação da PDVSA}

APDVSA foi criada por decreto-lei em 30/8/1975, com vigência a partir de 1/1/1976, e seu objetivo para extrair petróleo e liderar o processo de crescimento econômico do país. Na época, ela constituía uma holding que reunia 14 subsidiárias. Antes do final da década de 1970, o número dessas subsidiárias reduziu-se para três 
(Lagoven, Maraven e Corpoven); isso fez parte de um processo de racionalização da estrutura corporativa. Essas três companhias, por sua vez, são totalmente integradas verticalmente.

A estatal venezuelana é a terceira maior empresa petrolífera do mundo, de acordo com o ranking da Petroleum Intelligence Weekly (PIW). Na busca de vantagens competitivas, ela passou por três fases distintas. A primeira foi constituída por uma indústria verticalmente integrada e totalmente nacionalizada. Na segunda fase, na década de 1980, a empresa buscou a internacionalização da produção, através do aumento da participação no segmento downstream em mercados consumidores importantes. E, por fim, na década de 1990, ela abriu seu segmento upstream para investimentos estrangeiros, acompanhando a tendência mundial no setor (Rodrigues 1995).

\subsection{Atuação da empresa no segmento downstream}

A partir do início dos anos de 1980, a renda petrolífera começou a se reduzir pela internalização de fatores externos, o que agravou os desequilíbrios macroeconômicos. Esses desequilíbrios foram provocados pelos planos de ajuste econômico, por transferências governamentais e subsídios para determinados grupos sociais, o que aumentou os níveis de pobreza da maioria da população nacional. Cabe lembrar que em toda a América Latina essa década ficou conhecida como a "década perdida”. O crescimento médio anual do PIB venezuelano nessa década alcançou apenas 0,49\%. Essas políticas provocaram, em 1982, uma queda significativa dos preços do petróleo, apesar do aumento do volume de petróleo exportado (Clemente 2004:28).

Entre 1979 e 1982, a Venezuela diminuiu drasticamente as receitas oriundas do petróleo, principalmente pela redução das exportações aos Estados Unidos, o seu principal mercado. Isso ocorreu pelo fato dos americanos substituírem petróleo por carvão, considerado bem mais barato, e por maiores importações de petróleo mexicano, mais barato (Rodrigues 1995:75).

Em 1983 a Venezuela iniciou uma estratégia de cooperação com empresas independentes, que buscavam proteção em relação às incertezas do mercado e às variações dos preços do petróleo. Nesse mesmo ano, a PDVSA fechou o seu primeiro acordo para a formação de uma joint venture com o grupo Veba Oel AG, uma subsidiária do complexo energético alemão Veba AG. Porém, em 1985, a situação dos países da OPEP era crítica, pela obrigação de reduzir as cotas de produção. Diante dessa situação de crise, a PDVSA revisou as suas estratégias de produção e de comercialização, passando a priorizar as exportações de óleos pesados e extrapesados, como menor ênfase para as exportações de óleos leves e médios, que também tinham se tornado vulneráveis.

Diante dessa vulnerabilidade de colocação de petróleo no mercado internacional, a PDVSA continuou a busca de novos mercados no exterior, capazes de absorver seu crescente potencial de produção de óleos pesados e extrapesados. Em junho de 1986, a PDVSA adquiriu metade da AB Nynäs Petroleum, uma unidade 
pertencente ao complexo sueco de Axel Johnson, cuja participação restante foi comprada em fins de 1989 pela Companhia Neste Oel, de origem finlandesa. Essa participação acionária da PDVSA tinha como objetivo consolidar a posição venezuelana na exportação de petróleos pesados (Rodrigues 1995:93).

A PDVSA continuou expandindo as suas atividades no mercado internacional. Assim, em fins de 1988 ela assinou um contrato para formar uma joint venture com a Union Oil Corporation of Califórnia, Estados Unidos. No entanto, esse não foi o único investimento dessa estatal nos Estados Unidos. Em meados de 1986, a PDVSA e a Southland Corporation assinaram um acordo através do qual a primeira iria se tornar proprietária de 50\% da Citgo Petroleum Corporation, uma subsidiária da Southland localizada nos Estados Unidos. O grupo Citgo é o oitavo maior complexo de refino dos Estados Unidos, sendo também o quinto maior comerciante de gasolina desse país, com uma fatia de $8 \%$ do mercado (Rodrigues 1995:99).

A formação de joint ventures pela companhia mantém as vantagens da integração vertical para frente, além dos benefícios da cooperação. A empresa entrou, portanto, em um programa de internacionalização, nessa segunda fase da busca de vantagens competitivas. Entre 1983 e 1993, a empresa passou a controlar, total ou parcialmente, 16 refinarias e sistemas de distribuição e comercialização de petróleo (Rodrigues 1995:85).

A estratégia da busca de uma maior participação no segmento downstream, no exterior, permitiu à PDVSA reduzir significativamente sua vulnerabilidade, frente a um contexto de instabilidade e incertezas crescentes para a indústria petrolífera mundial. Os investimentos downstream da empresa no exterior tiveram uma contribuição importante na geração de receitas da companhia holding, o que não teria ocorrido caso a estratégia de quase-integração não tivesse sido levada adiante e a empresa preferisse continuar realizando a maioria de seus negócios via mercado internacional.

A grande vantagem alcançada pela PDVSA no segmento downstream foi a compensação de riscos do segmento usptream, estabilizando os lucros da empresa. Ela não se lançou internacionalmente como uma empresa completamente integrada verticalmente, mas a cooperação proporcionou-lhe o compartilhamento de riscos, de custos e de instalações que foram essenciais para o grande crescimento da empresa na década de 1980 e início dos anos de 1990.

\subsection{Atuação da PDVSA no segmento upstream}

A partir de 1989, com a queda do preço do petróleo, o país entrou em profunda crise econômica e política, agravada por uma sucessão de governos corruptos. Havia uma tendência à impunidade dos delinqüentes de colarinho branco. Isso revoltava os críticos por se tratar de um país endividado e pobre, pois para eles, assim como para segmentos importantes da população, é incompreensível que a riqueza petrolífera não consiga gerar maior bem-estar social e segurança. Os anos de 1990 iniciam-se com ajustes e reformas, como em outros países da América Latina. 
Esse período caracteriza-se por problemas de autofinanciamento einstabilidade política e econômica, provocada pelo governo neoliberal de Rafael Caldera, envolvido em processos de corrupção. Entre 1993/1994, os preços do petróleo reduziram-se no mercado internacional, o que afetou negativamente as exportações e a economia como um todo. Essa crise trouxe perdas sociais, particularmente para os trabalhadores, em virtude da redução da produtividade e dos postos de trabalho.

No início do ano de 1998, a PDVSA, seguindo um processo de abertura e reestruturação do setor petrolífero, apresentou uma nova estrutura: duas holdings, a PDV - Petróleo e Gás e a PDV - Química. Dessa maneira, desapareciam as três grandes filiais operadoras de petróleo (Maraven, Lagovem e Corpoven).

A instabilidade política e econômica e os envolvimentos com esquemas de corrupção provocaram novas eleições na Venezuela. Desse modo, as eleições de 1998 transcorreram caracterizadas pelo descrédito com os políticos vinculados à tradição política neoliberal e uma nova ideologia política nacionalista-progressista surgiu na figura do tenente coronel Hugo Chávez Frias.

Hugo Chávez tomou posse em fevereiro de 1999. A principal promessa de sua plataforma eleitoral foi a nacionalização efetiva do petróleo, a maior riqueza nacional, através do controle estatal completo da PDVSA. O novo governo herdou de Rafael Caldera a economia em uma situação muito difícil, tendo em vista que a maior fonte de receita do país, o petróleo, estava com os preços muito baixos, iguais a US $\$ 10,88$ o barril em 1/2/1999. ${ }^{8}$

Em dezembro de 1999, o governo Chávez criou o Fondo de Investimento para la Estabilización Macroeconómica (FIEM), composto pelos excedentes das divisas petroleiras. Esses recursos serviriam de garantia de futuras quedas de preços ou reduções quantitativas de petróleo exportado. Esse fundo permitiu um significativo aumento das receitas petrolíferas; a situação, que era de déficit em 1998, em torno de US\$ 3,2 bilhões, reverteu-se em 1999 para um superávit de US\$ 3,7 bilhões. Contudo, esse superávit não foi suficiente para melhorar os setores de mercado interno. Nesse mesmo mês, através de um referendo popular, Chávez promulgou uma nova Constituição, com forte teor nacionalista e reformador (Severo 2004:14).

A partir desse segundo mandato, Chávez iniciou uma política externa que denominou de "renascimento" da OPEP, procurando, com isso, a valorização dos preços do petróleo. Ele conseguiu nomear um aliado político para a presidência da OPEP, implantando a partir daí a chamada "linha Chávez" no organismo mundial. Entre 2000 e 2002, houve uma elevação significativa dos preços do petróleo, que passaram de US\$23,87 em 29/12/2000 para US\$ 28,66 em 31/12/2002.

8 Os preços do barril de petróleo (FOB) estavam ainda mais baixos um ano antes (US\$ 9,64 em 10/12/1998), sendo que em 31/1/1990 ele havia sido cotado a US\$20,06. Contudo, Chávez teve sorte porque em 30/12/1999 o preço do barril de petróleo estava custando US\$ 25,08 (Disponível em: < http://fgvdados.fgv.br/dsp_frs_ pai_ferramentas.asp. > Acessado em 23/11/2006.) 
No ano de 2001, o governo Chávez decretou nova Lei dos Hidrocarbonetos, que entrou em vigor em janeiro de 2002, em substituição à Lei de Hidrocarbonetos de 1943. A nova lei estabeleceu que a PDVSA pertence ao Estado e que todas as atividades da indústria petrolífera devem contar com maioria acionária do governo venezuelano. Pela nova lei, os royalties passaram de $16,6 \%$ para $30 \%$ e o imposto de renda foi reduzido de $67 \%$ para $50 \%$. Esse abrandamento da carga fiscal mostra, claramente, uma mudança de postura do governo em relação ao setor petrolífero. A reforma tributária não foi suficiente para que a economia venezuelana recuperasse o fôlego financeiro, para que a empresa obtivesse os recursos necessários para intensificar a exploração e o desenvolvimento de suas reservas. Assim, o governo venezuelano resolveu estimular a formação de associações com o capital estrangeiro no segmento upstream.

A abertura do setor aos investimentos estrangeiros no segmento upstream marcou a terceira fase da PDVSA. A estratégia upstream tinha como objetivo principal aumentar os recursos da companhia, permitir o aumento dos investimentos na exploração petrolífera e gerar resultados positivos na balança comercial, impulsionando o desenvolvimento econômico do país.

Com a abertura do segmento upstream ao capital privado, a produção de petróleo elevou-se rapidamente. ${ }^{9}$ Entre as vantagens no segmento upstream está a ampliação da posição competitiva da PDVSA, ao gerar maiores economias de escala, acesso a novas tecnologias e a equipamentos, além do compartilhamento de riscos, custos e lucros. Por outro lado, a abertura ao segmento uspstream também gerou desvantagens, tais como riscos de relações oportunísticas, elevados custos de comprometimento e aumento das barreiras à saída. O segmento upstream trouxe, ainda, outros problemas, como a possibilidade do esgotamento progressivo das reservas na Venezuela, se não forem feitas novas descobertas. Além disso, há a perda de controle sobre a política energética. A diminuição da coordenação e do controle de todas as etapas da cadeia produtiva é também uma conseqüência negativa dessa estratégia (Rodrigues apud Freitas 2003:64).

O quadro de evolução da economia venezuelana sofreu poucas alterações até os dias atuais. O preço do barril de petróleo, que custava US $\$ 30$ em dezembro de 2003, subiu para US\$ 40 em dezembro de 2004, US\$ 59 em dezembro de 2005, para ultrapassar os US\$ 70 dólares em 2006. Na ausência de um plano de desenvolvimento econômico que absorvesse volumes substanciais de investimentos, a grande capacidade de importar continua inibindo a indústria nacional. O petróleo continua representando mais de $80 \%$ das receitas de exportação e das receitas fiscais do governo. A indústria petrolífera venezuelana continua cada vez mais oligopolizada e altamente integrada verticalmente.

9 As modalidades de abertura nesse segmento foram convênios operativos, associações estratégicas, convênios de lucros compartilhados e convênios de comercialização de combustíveis extrapesados (Campos 2005:192). 


\section{Considerações finais}

Este artigo estudou as abordagens referentes à empresa apresentadas pela nova economia institucional. Estudou-se essa nova abordagem tendo como exemplo a indústria petrolífera venezuelana, procurando identificar suas estratégias organizacionais, tendo em vista a necessidade de busca constante de maior competitividade no contexto de um mundo cada vez mais globalizado. A teoria econômica neoclássica desconsiderava a existência de custos de transação. A nova economia institucional emerge no cenário da análise econômica aferindo um importante papel à firma e ao comportamento dos tomadores de decisão, de forma a aproximar o diagnóstico do que é realmente observado no mundo real.

Historicamente, a indústria do petróleo caracterizou-se pela integração vertical e por complexos contratos de longo prazo. A integração vertical gerava estabilidade para as firmas e permitia a execução de volumosos investimentos na construção de infra-estrutura de transporte e de distribuição, com o fim de minimizar as incertezas e os incentivos a comportamentos oportunistas.

Esse procedimento vinha sendo adotado na Venezuela até há pouco tempo. Nos últimos anos, a empresa Petróleos da Venezuela (PDVSA) precisou se adaptar às novas formas organizacionais, como todas as demais empresas do ramo petrolífero em todo o mundo. Como a integração vertical, para trás e para frente, envolve um volume muito grande de capitais, a forma encontrada foi a associação com outras empresas, na maior parte dos casos de outros países. Essas associações são feitas para o exercício de atividades dentro e fora da Venezuela.

Como o petróleo é a principal fonte de renda da Venezuela, ele se tornou um bem de utilidade pública. Desse modo, o Estado vem interferindo cada vez mais na função regulatória, fomentando os investimentos e a eficiência alocativa nesse setor altamente oligopolizado e verticalizado. A PDVSA é uma empresa atuante em todo o mundo e possui uma estrutura verticalmente integrada. De acordo com Rodrigues (1995:142) "a posição de destaque que a PDVSA assume hoje deve-se, em grande parte, à sua preocupação com um significativo grau de integração vertical".

A partir da década de 1980, a empresa procurou diversificar seus investimentos de forma cada vez mais integrada verticalmente, a fim de assegurar competitividade crescente. Essa estratégia contribuiu para a sua decisão de internacionalizarse, aumentando sua participação inicialmente no segmento downstream; isso ocorreu em mercados consumidores importantes, através de joint ventures; os principais sócios foram os grupos Veba Oel AG, Nynas e Citgo.

A estratégia da busca de maior participação no segmento downstream, no exterior, permitiu à PDVSA reduzir significativamente sua vulnerabilidade, frente a um contexto de instabilidade e incertezas crescentes para a indústria 
petrolífera mundial. A PDVSA obteve grandes vantagens competitivas no segmento downstream; isso se explica porque ela pôde usufruir de economias de aglomeração, economias de escala, aprendizado tecnológico, além de compartilhamento de riscos e de custos e acesso a recursos para financiamento de terceiros. Teria sido impossível à empresa alcançar tais vantagens se tivesse seguido a integração vertical na forma tradicional.

No contexto do Mercosul, por exemplo, o objetivo do governo venezuelano tem sido consolidar sua aliança política através do Brasil. Nesse sentido, a estatal consolida seus negócios com a Petrobras, concentrados no segmento downstream.

Pode-se perceber que, no curto prazo, a liberalização das associações no segmento downstream não significou mudanças drásticas na competitividade da indústria petrolífera venezuelana. Inclusive, a Constituição venezuelana atual proíbe a privatização da empresa. Pela nova Lei dos Hidrocarbonetos de 2001, a PDVSA pertence exclusivamente ao Estado e todas as atividades petrolíferas devem contar com maioria acionária do governo venezuelano. Por essa lei, ficam definidos pontos fundamentais como o aumento dos royalties destinados ao governo e redução do imposto de renda. Contudo, essas medidas não têm gerado recursos suficientes para intensificar a exploração de novos poços de petróleo.

A estatal pretendia maximizar a apropriação da renda petrolífera pelo Estado e gerar divisas suficientes para impulsionar o desenvolvimento econômico do país, o que passou a ser a principal justificativa, a partir de 1992, para a abertura aos investimentos estrangeiros no segmento upstream, através da formação de joint ventures. Isso marcou a terceira fase da PDVSA na adoção da estratégia mais dinâmica e competitiva do setor petrolífero.

A abertura no segmento upstream ampliou a posição competitiva da PDVSA. Essa estratégia gerou novas economias de escala e permitiu o acesso a novas tecnologias e equipamentos, além do compartilhamento de riscos, custos e lucros. Porém, a abertura nesse segmento poderá acarretar um risco crucial para a indústria venezuelana: a exploração indiscriminada de petróleo e gás poderá, no longo prazo, provocar o esgotamento das reservas, se não forem feitas novas descobertas. Logo, a estratégia de abertura no segmento upstream, sendo mal conduzida, poderá levar, no longo prazo, à deterioração das vantagens competitivas inerentes à integração vertical da indústria do petróleo.

Como se percebe, a estratégia adotada pela PDVSA, com associações nos segmentos upstream e downstream, consolidou a indústria petrolífera venezuelana através de uma estrutura verticalmente integrada, seguindo a nova economia institucional. A tendência de integração vertical na indústria de petróleo é nítida, dada a grande especificidade dos ativos envolvidos em todos os elos da cadeia (atividades de exploração, produção, processamento e escoamento da produção). A indústria de petróleo, além de verticalmente 
integralizada, encontra-se fortemente concentrada. No caso da Venezuela, essa concentração de renda das exportações petrolíferas gera sérios problemas aos demais setores econômicos, porque o excesso de divisas valoriza o câmbio, o que barateia as importações e inibe o crescimento das indústrias de mercado interno produtoras de bens de consumo.

\section{Referências}

ASSOCIAÇÃO LATINO-AMERICANA DE INTEGRAÇÃO - ALADI. URL [On line]: http://www.aladi.org. Acesso em: 23 de janeiro de 2007.

CAMPOS, Adriana F. (2005). A reestruturação da indústria de petróleo sul-americana nos anos 90. Tese (Doutorado em Planejamento Energético) - COPPE/UFRJ, Rio de Janeiro.

CANELAS, André L. S. (2004). Investimentos em exploração e produção após a abertura da indústria petrolifera do Brasil: impactos econômicos. Monografia de Bacharelado - Instituto de Economia, UFRJ.

CANO, Wilson (2000). Soberania e política econômica na América Latina. São Paulo: UNESP.

(2001). "Venezuela: limites para uma nova política econômica." Economia e Sociedade, Campinas, UNICAMP.

CARO, Ariela R. (2003). Tendências recientes del mercado internacional del petróleo. Santiago do Chile: Publicación de las Naciones Unidas.

CLEMENTE, R. (2004). "Crecimiento económico y productividad en Venezuela, 19502000." Revista del Banco Central de Venezuela 18(1): 13-40.

COASE, Ronald H. (1937). "The nature of the firm.” Economica 4(16):386-405.

FGVDADOS. Cotação diária do Petróleo tipo Brent. URL [On line]: http://fgvdados.fgv. br/dsp_frs_pai_ferramentas.asp. Acesso em: 23 de novembro de 2006.

FIANI, R. (2002). “Teoria dos custos de transação.” In KUPFER, D. \& HASENCLEVER, L. Economia industrial: fundamentos teóricos e práticas no Brasil. Rio de Janeiro: Campus.

FREITAS, Regina V. (2003). As estratégias empresariais de cooperação e integração vertical: o caso da indústria de petróleo do Brasil. Monografia de Bacharelado Instituto de Economia, UFRJ, Rio de Janeiro.

GUIMARÃES, Samuel P. (Org.) (1995). Brasil e Venezuela: esperanças e determinação na virada do século. Brasília: IPRI-FUNAG.

LATIN-FOCUS. Consensus Forecast. URL [On line]: http://www.latinfocus.com/spanish/ countries/venezuela/ veneisum.htm. Acesso em: 30 de novembro de 2006.

MACADAR, Jaime Adrian M. (2005) "Da teoria neoclássica da firma ao paradigma do oligopólio: refazendo o percurso do surgimento da economia industrial." Revista dos Estudantes do Curso de Graduação em Economia da Faculdade de Ciências Econômicas, UFRGS, 4(2). 
MACHER, Jeffrey \& RICHMAN, Barak. Transaction cost economics: an assessment of empirical research in the social sciences. URL [On line]: http://faculty.msb.edu/jtm4/ Papers/ MR.JEL.2006.pdf. Acesso em: 19 de abril de 2007.

MARCANO, Cristina \& TYSZKA, Alberto B. (2006). Hugo Chávez sem uniforme: uma história pessoal. Rio de Janeiro: Gryphus.

MARINHO JÚNIOR, Ilmar P. (1989). Petróleo: politica e poder (um novo choque do petróleo). Rio de Janeiro: J. Olympio.

PETERSON, Luzitisana L. (2004). A relação entre o crescimento econômico e a produção de petróleo: 1980/1995. Monografia de Economia - PUCRS, Porto Alegre.

RODRIGUES, Gisele M. (1995). Integração vertical e inovações organizacionais: o caso da Petróleos de Venezuela (PVSA). Dissertação de Mestrado - Instituto de Economia, UFRJ.

SEVERO, Luciano W. (2004). A política econômica do governo Chávez. República Bolivariana de Venezuela, Ministerio de Finanzas. URL [On line]: www. alternativaboliviariana.org/pdf/ politicaeconomica.pdf. Acesso em: 25 de outubro de 2006.

TIGRE, Paulo Bastos (2005). "Paradigmas tecnológicos e teorias econômicas da firma." Revista Brasileira de Inovação 4(1).

WILLIAMSON, Oliver (1985). The economic institutions of capitalism: firms, markets, relational contracting. New York: Free Press.

(1989). "Transaction Cost Economics." In SCHMALENSEE, R. \& WILLIG, R. (Ed.). Handbook of Industrial Organization. Amsterdam: North Holland. v. 1: 135-82.

Submissão: 15 de março de 2007

Primeira resposta: 16 de abril de 2007

Aceite: 2 de maio de 2007 